\title{
Article
}

\section{The influence of carbon nanotubes on the combustion toxicity of PP/intumescent flame retardant composites}

Zhang, Qiangjun, Zhan, Jing, Zhou, Keqing, Lu, Hongdian, Zeng, Wenru, Stec, Anna A, Hull, T Richard, Hu, Yuan and Gui, Zhou Available at http://clok.uclan.ac.uk/13274/

Zhang, Qiangjun, Zhan, Jing, Zhou, Keqing, Lu, Hongdian, Zeng, Wenru, Stec, Anna A ORCID: 0000-0002-6861-0468, Hull, T Richard ORCID: 0000-00027970-4208, Hu, Yuan and Gui, Zhou (2015) The influence of carbon nanotubes on the combustion toxicity of PP/intumescent flame retardant composites. Polymer Degradation and Stability, 115 . pp. 38-44. ISSN 01413910

It is advisable to refer to the publisher's version if you intend to cite from the work. http://dx.doi.org/10.1016/j.polymdegradstab.2015.02.010

For more information about UCLan's research in this area go to http://www.uclan.ac.uk/researchgroups/ and search for <name of research Group>.

For information about Research generally at UCLan please go to http://www.uclan.ac.uk/research/

All outputs in CLoK are protected by Intellectual Property Rights law, including Copyright law. Copyright, IPR and Moral Rights for the works on this site are retained by the individual authors and/or other copyright owners. Terms and conditions for use of this material are defined in the policies page. 
Publication Information: Zhang Q., Zhan J., Zhou K., Lu H., Zeng W., Stec A.A., Hull T.R., Hu Y., Gui Z. The influence of carbon nanotubes on the combustion toxicity of PP/intumescent flame retardant composites (2015) Polymer Degradation and Stability, 115, pp. 38-44.

\title{
The influence of carbon nanotubes on the combustion toxicity of PP/intumescent flame retardant composites
}

\section{Qiangjun Zhang ${ }^{a}$, Jing Zhan ${ }^{\text {a,d, }}$ Keqing Zhou ${ }^{a}$, Hongdian Lu ${ }^{b}$, Wenru Zeng ${ }^{a}$, Anna} A. Stec ${ }^{c}$, T. Richard Hull ${ }^{c}$, Yuan Hu ${ }^{\text {a,* }}$, Zhou Gui ${ }^{\text {a,* }}$

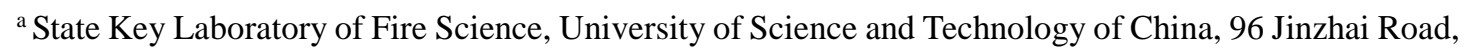
Hefei, Anhui, 230026, P. R. China

${ }^{\mathrm{b}}$ Department of Chemical and Materials Engineering, Hefei University, Hefei, Anhui, 230601, P. R. China

${ }^{\mathrm{c}}$ Center for Fire and Hazards Science, University of Central Lancashire, Preston PR1 2HE, UK

${ }^{d}$ School of Civil Engineering and Environmental Engineering, Anhui Xinhua University, Hefei 230088, China

\section{Corresponding Author:}

* E-mail address: yuanhu@ustc.edu.cn (Yuan Hu). Tel.: +86-551-63601664; Fax: +86-551-3601664.

E-mail address: zgui@ustc.edu.cn (Zhou Gui).Tel.: +86-551-63601288; Fax: +86-551-3601669.

\begin{abstract}
In recent years, carbon nanotubes (CNTs) have emerged as a promising candidate for improving the flame retardancy of polymer materials, as well as other physical properties. However, few researches have been focused on the influence of this nanoscale material on the combustion toxicity of polymer composites during combustion. In this work, the fire toxicity of polypropylene (PP) composites with intumescent flame retardants (IFRs) and CNTs has been investigated by a Purser Furnace apparatus, which is called steady state tube furnace (SSTF) and enables different fire stages to be created. The Thermo gravimetric analyzer (TGA) and derivative thermo gravimetric analysis (DTG) data indicate that the thermal stability of PP composites was increased by the addition of IFRs or CNTs. However, the SSTF results show that PP samples with IFR or CNTs or both, produced much more carbon monoxide (CO) compared to neat PP during all fire stages, resulting in a much lower $\mathrm{CO}_{2} / \mathrm{CO}$ ratio. Furthermore, an interesting finding is that the effect of CNTs on the smoke production and $\mathrm{C}_{\mathrm{x}} \mathrm{H}_{\mathrm{y}}$ yield of the PP samples during the combustion changes with the combustion equivalence ratio. It indicates that the presence of CNTs promote the formation of smoke particulates from hydrocarbon, but this effect only exist when oxygen supply is not adequate. It is also concluded that the air ventilation and combustion temperature play significant roles in the fire effluent production of PP samples and the morphology of soot particulates.
\end{abstract}

Keywords: Intumescent fire retardant; Steady state tube furnace; Smoke; CO; Hydrocarbon; Soot; CNTs 


\section{Introduction}

Polypropylene (PP) is a widely used synthetic polymer, and has been applied in many fields, such as industry, construction, electronic devices. To meet the growing requirement of addressing the flammability of all materials, particularly for the synthetic polymeric materials, flame retardant technology has been a substantial development in recent years. The IFRs, typically consisting of three ingredients: acid source, carbon source and blowing agent, have become the major choice as non-halogen flame retardants for PP [1-3]. In recent years, nano materials have attracted considerable attention as the next generation of reinforcement materials for polymer. The addition of nanoscale materials, such as CNTs and graphene can significantly enhance the flame retardant, electrical, thermal properties, etc. of polymers, and thereby the applications of polymer materials are broadened [4-6]. Few researches has been done on the fire toxicity of these polymer composites during the combustion, however, fire toxicity has been proved to be the main cause of fire death [7, 8].

In general, fire toxic gases contain the following two parts :

1. Asphyxiants: CO, hydrogen cyanide (HCN).

2. Irritants: hydrogen chloride ( $\mathrm{HCl})$, hydrogen bromide $(\mathrm{HBr})$, organic irritants (acrolein and formaldehyde, etc.), oxides of nitrogen $\left(\mathrm{NO}_{\mathrm{x}}\right)$ and sulphur $\left(\mathrm{SO}_{\mathrm{x}}\right)$.

Among these toxic gases, $\mathrm{CO}$ is generally considered to cause the greatest number of fire deaths, because it can impede escape and intensely increase the chance of becoming trapped [9]. Fire effluents, including particulate matter, can penetrate deep into lung, and cause interstitial and luminal oedema [10].

The real fire develops from smoldering combustion and early well-ventilated flaming, to fully develop under-ventilated flaming. The under-ventilated stage has been considered to be the most toxic fire stage. In prior publications, cone calorimeter and NBS smoke chamber are usually used to assess the fire toxicity of polymer composites. However, it is difficult for these bench-scale test models to replicate certain fire stages, which would result in the uncertainty and unreliable test data to reflect the combustion toxicity of samples in real fire.

The steady state tube furnace (SSTF) (BS 7790 and ISO TS 19700) used in this article is both a standard test apparatus and research tool that can provide building engineers and designers with valuable data of fire hazard. The significant advantage of this apparatus over other techniques is its capability to replicate each stage of fire development [11, 12]. The SSTF has been used by Hull T.R. and Stec A.A. to study the combustion toxicity of PP, polyamide 6 (PA6), polyvinyl chloride polymer (PVC) and ethylene-vinyl acetate copolymer (EVA) composites with some fillers, such as clay, halogen flame retardants, aluminium hypophosphite [13-16].

The SSTF is capable of directly controlling of the furnace temperature, fuel mass and air supply. Although the flaming fires are broadly classified as well-ventilated and under-ventilated fire, a more sophisticated equivalence ratio $\phi$ is employed to define different fire stages in ISO 19700 tube furnace standard.

$$
\phi=\frac{\text { actual fuel } / \text { air } \text { ratio }}{\text { stoichiometric fuel } / \text { air ratio }}
$$


Where $\phi=1$ : 'stoichiometric' combustion; $\phi<1$ : well-ventilated fires (fuel lean flames); and $\phi>1$ : under vitiated fires (fuel-rich flames). It is well established the fire effluents are critically dependent on this ratio.

The aims of this work are to investigate the effect of the additives (CNTs, IFR), equivalence ratio and temperature the fire toxicity of PP composites, and to make accurate assessment of the fire safety of these composites. The present work will give rise to a better understanding of the combustion mechanism of polymeric composites.

\section{Experimental}

\subsection{Materials}

The virgin PP (F401 homopolymer) was supplied as pellets by Yangzi Petrochemical Co., Ltd. (China). Maleic anhydride grafted polypropylene (MAPP, 1.0-2.0 MA \%) was kindly provided by Keyan Company (China). Ammonium polyphosphate (APP, phase II) form was supplied by JLS Company. Pentaerythrite (PER) was obtained from Ruiyang Chemical Company. Multi-walled Carbon Nanotubes (MWNTs) was purchased from BASF, with the diameter being 20-50 nm, and the length being at least of the order of micrometers. Xylene and sulfuric acid $\left(\mathrm{H}_{2} \mathrm{SO}_{4}, 98 \%\right)$ were purchased from Sinopharm Chemical Reagent Co., Ltd. (China). Nitric acid $\left(\mathrm{HNO}_{3}, 98 \%\right)$ was bought from Guangfu Fine Chemical Research Institute (China).

\subsection{Preparation of PP nanocomposites}

The MWNTs was purified and acidified by $\mathrm{H}_{2} \mathrm{SO}_{4}$ and $\mathrm{HNO}_{3}$ (1:3 by volume) in an ultrasonic bath at $50{ }^{\circ} \mathrm{C}$ for $4 \mathrm{~h}$, after that, it was then filtrated. The excess acid was washed thoroughly with deionized water until the $\mathrm{pH}$ value reached 7. The acid-treated MWNTs (a-MWNTs) were dried at $80^{\circ} \mathrm{C}$ in a vacuum oven overnight and then grinded into powder with a carnelian mortar.

The PP/CNTs nanocomposites were prepared by masterbatch-melt blending process, as shown in Figure 1. Firstly, $1.0 \mathrm{~g}$ a-MWNTs were dispersed in $110 \mathrm{~mL}$ xylene in a three-necked round-bottom flask via vigorous ultrasonication and stirring at $135{ }^{\circ} \mathrm{C}$. Then, $9.0 \mathrm{~g}$ PP was added to the above dispersion. After ultrasonication and stirring for $2 \mathrm{~h}$, the black slurry obtained was dried in an oven at $120^{\circ} \mathrm{C}$ for $12 \mathrm{~h}$, then cut into small platelets and further dried at $130^{\circ} \mathrm{C}$ in a vacuum oven for $6 \mathrm{~h}$. The mass fraction of a-MWNTs in the masterbatch is $10 \mathrm{wt} \%$.

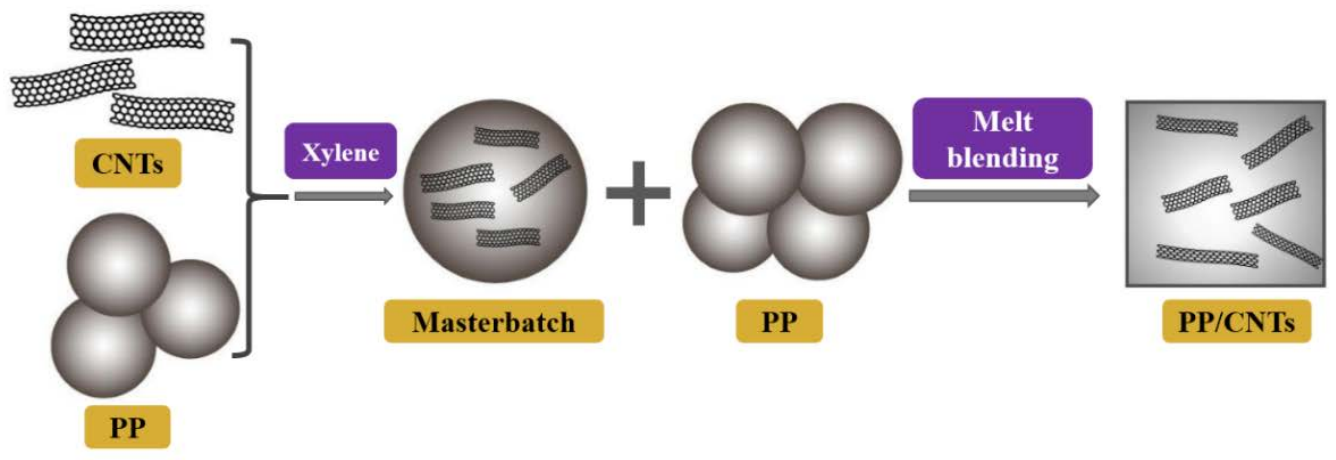

Figure 1 Preparation of PP/CNTs nanocomposites 
PP, MAPP, APP and PER were dried at $60^{\circ} \mathrm{C}$ for $6 \mathrm{~h}$ before use. PP composites were prepared by melt blending using a twin-roller Banbury mixer (SU-70ML, Changzhou Suyuan Rubber and Plastic Science and Technology Co., Ltd.). Firstly, PP and MAPP were melted at $180^{\circ} \mathrm{C}$ for $2 \mathrm{~min}$, with a roller speed of $100 \mathrm{rpm}$. Then flame retardants and the CNT masterbatch were fed into the mixer and further blended for $10 \mathrm{~min}$. The formulations are listed in Table 1.

Table 1 Formulation of various PP composites

\begin{tabular}{|l|c|c|c|c|c|}
\hline Sample & PP wt \% & MAPP wt \% & APP wt\% & PER wt\% & CNTs wt \% \\
\hline PP & 100 & 0 & 0 & 0 & 0 \\
\hline PP/CNTs & 94 & 5 & 0 & 0 & 1 \\
\hline PP/IFR & 70 & 5 & 16.7 & 8.3 & 0 \\
\hline PP/IFR/CNTs & 70 & 5 & 16 & 8 & 1 \\
\hline
\end{tabular}

\subsection{Characterization and measurements}

TGA tests were conducted using a TA Q5000 IR (TA instruments) thermo-analyzer. The samples (approximately $5 \mathrm{mg}$ ) were heated from 30 to $700^{\circ} \mathrm{C}$ at a linear heating rate of $20^{\circ} \mathrm{C}$ $/$ min under an air flow of $60 \mathrm{~mL} / \mathrm{min}$. The samples were run in triplicate, the temperature reproducibility of the instrument is $\pm 1^{\circ} \mathrm{C}$, while the mass reproducibility is $\pm 0.2 \%$.

The morphologies of the soot particulates of PP composites after combustion were observed using a JSM-6800 F scanning electron microscope（SEM） produced by JEOL. The surfaces of the samples tested were first sputter-coated with a thin layer of gold before the observation.

Transmission electron microscopy (TEM, JEM-2100F, Japan Electron Optics Laboratory Co., Ltd.) was employed to investigate the micro-morphology of the PP nanocomposites. PP/CNTs nanocomposites was cut into ultrathin sections using a CM1900 microtome (Leica, Wetzlar, Germany). The ultrathin sections were transferred from water to carbon-coated copper grids and then observed by TEM.

The SSTF in Figure 2 is a small-scale fire apparatus designed to replicate the different stages of fire. Fuel and air are introduced into the furnace at a certain ratio, enabling the equivalence ratio $\phi$ to be controlled, based on the knowledge of the material composition and its stoichiometric oxygen requirement. The samples in the form of granules or pellets are gradually introduced into the tube furnace at a constant feed rate. A current of air is passed through the furnace over the specimen to support combustion. The combustion effluent is expelled from the tube furnace into a mixing and measurement chamber, where it is diluted by secondary air flow. The decomposition conditions in the furnace are set by using various combinations of temperature, feed rate and air flow in separate runs, in order to simulate different range of fire stages as required. For these experiments, the corresponding experimental parameters are listed in Table 2. 


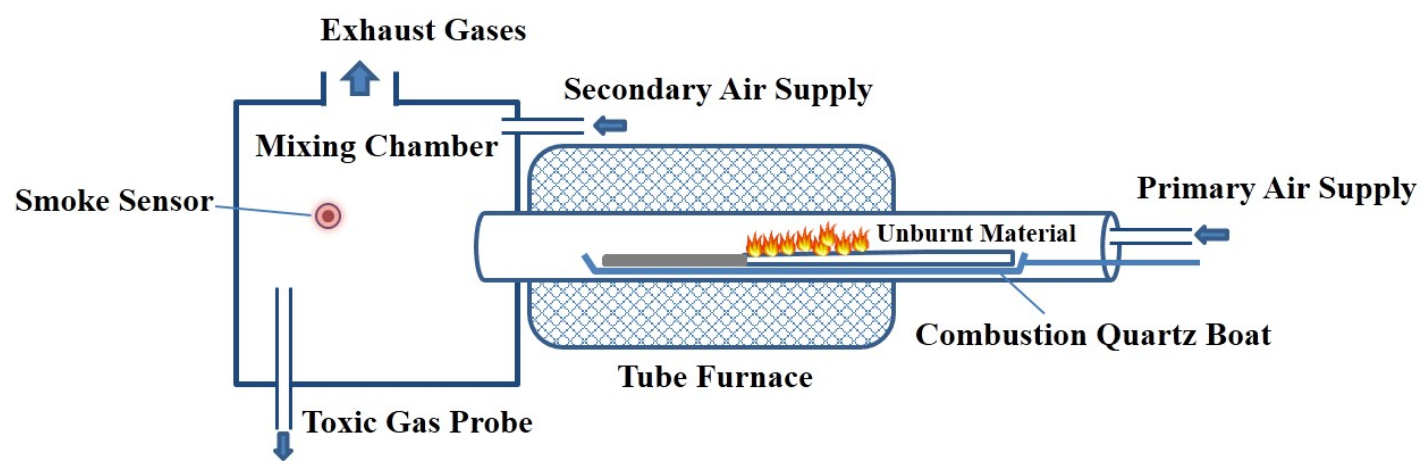

Figure 2 ISO 19700 Steady State Tube Furnace apparatus

Table 2 SSTF experimental parameters for each equivalence ratio $\phi$

\begin{tabular}{|l|c|c|c|}
\hline $\boldsymbol{\phi}$ & $\begin{array}{c}\text { Mass of PP } \\
\mathbf{( g )}\end{array}$ & $\begin{array}{c}\text { Feed rate } \\
\mathbf{( c m} / \mathbf{m i n})\end{array}$ & $\begin{array}{c}\text { primary air-flow } \\
(\mathbf{L} / \mathbf{m i n})\end{array}$ \\
\hline $\mathbf{0 . 5}$ & 11 & 3 & 10 \\
\hline $\mathbf{0 . 7 5}$ & 11 & 3 & 10 \\
\hline $\mathbf{1 . 5}$ & 16 & 3 & 3.5 \\
\hline $\mathbf{2 . 0}$ & 16 & 3 & 3.5 \\
\hline
\end{tabular}

Three fire stages are defined according to ISO 19706:
Well-ventilated:
$\phi<1,650{ }^{\circ} \mathrm{C}$;
Small under-ventilated: $\quad \phi>1,650^{\circ} \mathrm{C}$;
Large under-ventilated: $\quad \phi>1,825^{\circ} \mathrm{C}$.

Fire effluent was drawn through at a flow rate of $2.0 \mathrm{~L} \mathrm{~min}^{-1}$ for a period of $20 \mathrm{~min}$ during the steady state stage. Non-dispersive infrared (NDIR) (Gasboard-3100, Wuhan cubic optoelectronics Co., Ltd.) and was used to quantify the combustion products. A laser light and photo cell system was used to determine smoke density across the mixing and measurement chamber. $\mathrm{C}_{\mathrm{x}} \mathrm{H}_{\mathrm{y}}$ concentration was detected by an electrochemical analyzer (KM-9106, Kane International Ltd.), and recorded the average during 5 minutes at steady state. Soot particulates were collected by Whatman glass microfiber.

\section{Results and discussion}

\subsection{The dispersion of CNTs in PP matrix}

Figure 3 shows the TEM image of the ultrathin section of PP composite with $1 \mathrm{wt} \%$ a-MWNT. By acidified modification of CNTs and masterbatch preparation method, it is clear that the a-MWNT is dispersed individually and homogeneously throughout the PP matrix with an average bundle diameter of $40 \mathrm{~nm}$. 


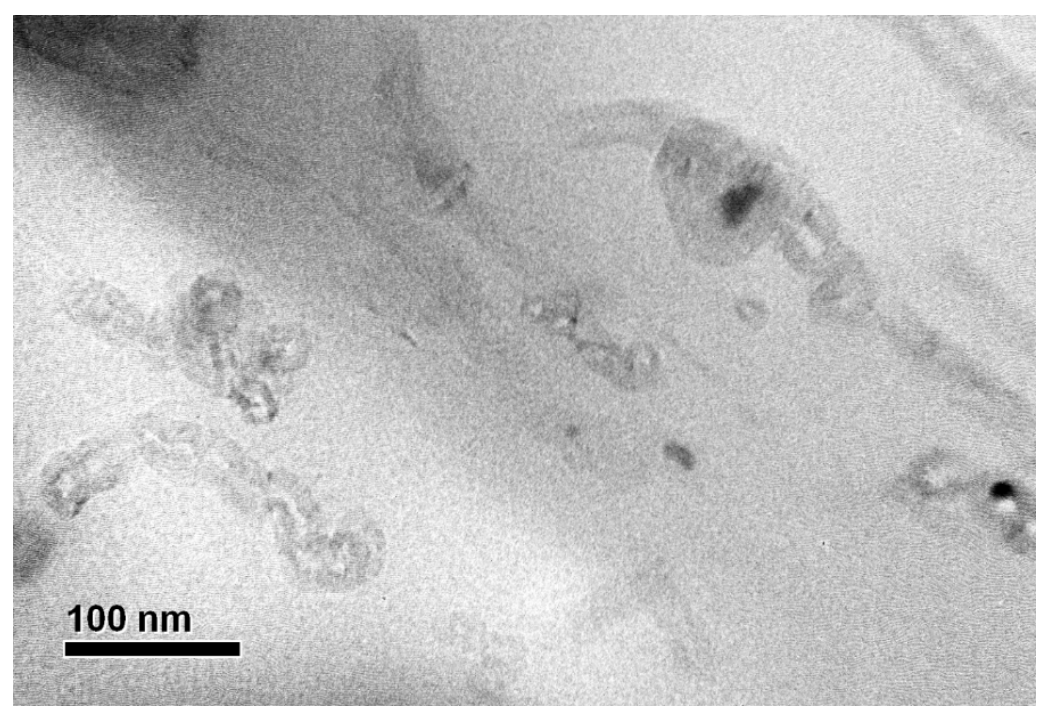

Figure 3 TEM image of PP composite with 1 wt\% a-MWNT

\subsection{Thermal Properties}

As shown in Figure 4a, the neat PP shows one-step mass loss in the temperature range of 265-370 ${ }^{\circ} \mathrm{C}$, while the PP/IFR sample shows a first step of small mass loss between 150 and $260^{\circ} \mathrm{C}$, followed by a rapid mass loss between 300 and $440^{\circ} \mathrm{C}$. The first stage decomposition may be attributed to the phosphorylation reaction of PER by APP with the release of $\mathrm{H}_{2} \mathrm{O}$ and $\mathrm{NH}_{3}$. And the latter may be due to further dehydration, deamination and phosphorylation, finally leading to the formation of cross-linking structures [17].

a

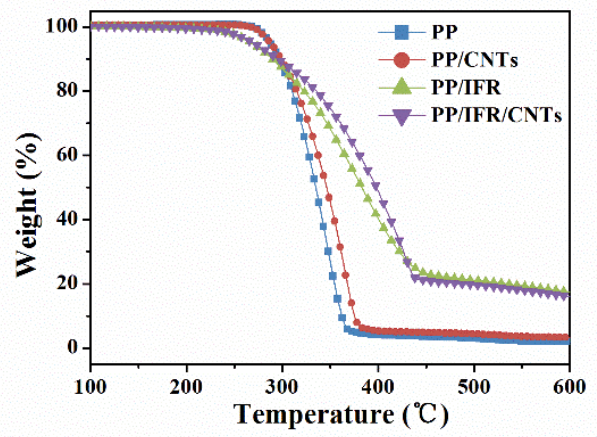

b

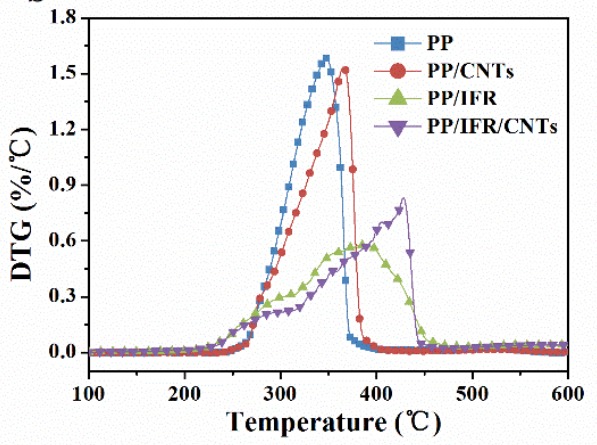

Figure 4 (a) TGA and (b) DTG curves of PP with IFR and CNTs additives

From the data in Table 3, it is obvious that PP samples with CNTs exhibit higher $\mathrm{T}_{50}$ and $\mathrm{T}_{\max }$ compared with those without CNTs, which means an improved thermal stability of the composites. The addition of CNTs significantly hinders the thermo-oxidation of PP and PP/IFR in the stages of decomposition. The prior studies have demonstrated that CNTs may easily trap a number of free radicals and decrease the decomposition rate of PP, thus enhancing its thermal stability $[18,19]$. 
Table 3 TGA and DTG data of PP and its composites under air atmosphere.

\begin{tabular}{|l|l|l|l|}
\hline Sample & $\mathbf{T}_{\mathbf{1 0}}\left({ }^{\mathbf{}} \mathbf{C}\right)$ & $\mathbf{T}_{\mathbf{5 0}}\left({ }^{\mathbf{}} \mathbf{C}\right)$ & $\mathbf{T}_{\max }\left({ }^{\mathbf{}} \mathbf{C}\right)$ \\
\hline PP & 297.1 & 334.8 & 348.2 \\
\hline PP/CNTs & 298.8 & 346.0 & 365.7 \\
\hline PP/IFR & 289.6 & 382.9 & 384.5 \\
\hline PP/IFR/CNTs & 295.1 & 397.9 & 428.7 \\
\hline
\end{tabular}

$\mathrm{T}_{10}$ : the temperature obtained from TGA curves at which $10 \%$ mass loss occurs;

$\mathrm{T}_{50}$ : the temperature obtained from TGA curves at which $50 \%$ mass loss occurs;

$\mathrm{T}_{\text {max }}$ : the temperature obtained from DTG curves at which the maximum mass loss rate occurs;

\subsection{Toxic product and Smoke}

The SSTF method (ISO 19700) relies on the establishment of a steady state for at least $5 \mathrm{~min}$ in 20 min burning time. It is important to recognize that all the samples should maintain the same PP mass. The yields of toxic effluent were expressed as grams per gram of polymer, rather than as grams per gram of sample.

\section{$\mathrm{O}_{2}$ consumption and $\mathrm{CO}_{2}$ Yield}

From Figure 5 and 6, it is evident that the $\mathrm{O}_{2}$ consumption and $\mathrm{CO}_{2}$ yield for all the PP samples show a uniformly decreasing trend as the equivalence ratio increases, indicating that the combustion efficiency is highly dependent on this ratio. CNTs and IFR have different effect on the combustion of PP especially for the different fire conditions. For well-ventilated conditions $(\phi<1)$, the presence of IFR and CNTs result in higher $\mathrm{O}_{2}$ consumption and $\mathrm{CO}_{2}$ yield. However, for the ventilated conditions $(\phi>1)$, opposite effect is found. Furthermore, the combustion temperature has an unmarked effect.

The lower combustion efficiency under-ventilated condition may be attributed to the formation of a protective char residue by IFR, and the introduction of CNTs can further promote the formation of this protective layer, due to its net structure in the PP matrix. However, when the oxygen supply is enough, the combustion of PP samples becomes so rapid that the protective layer cannot be formed in time. 


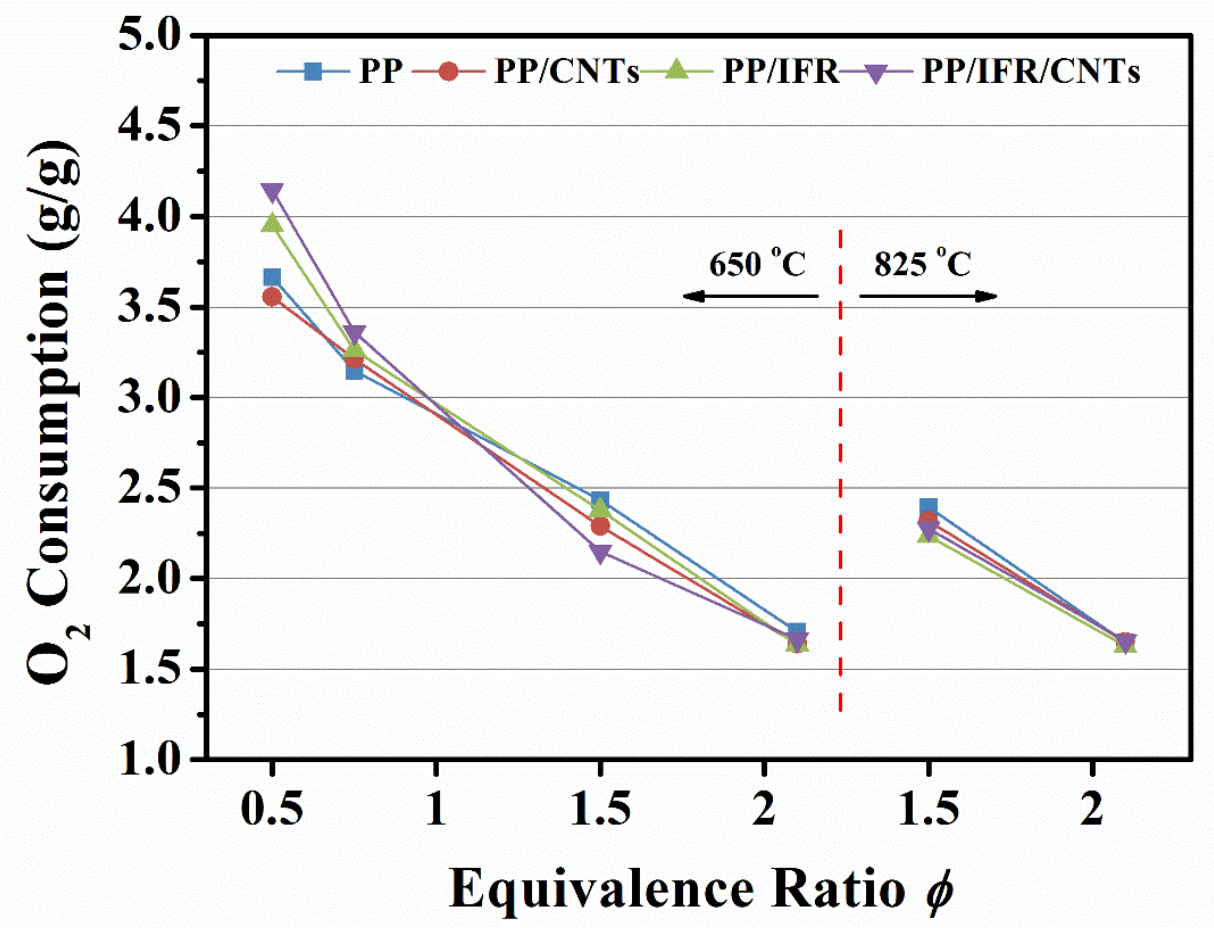

Figure $5 \mathrm{O}_{2}$ consumption of PP with IFR and CNTs additives

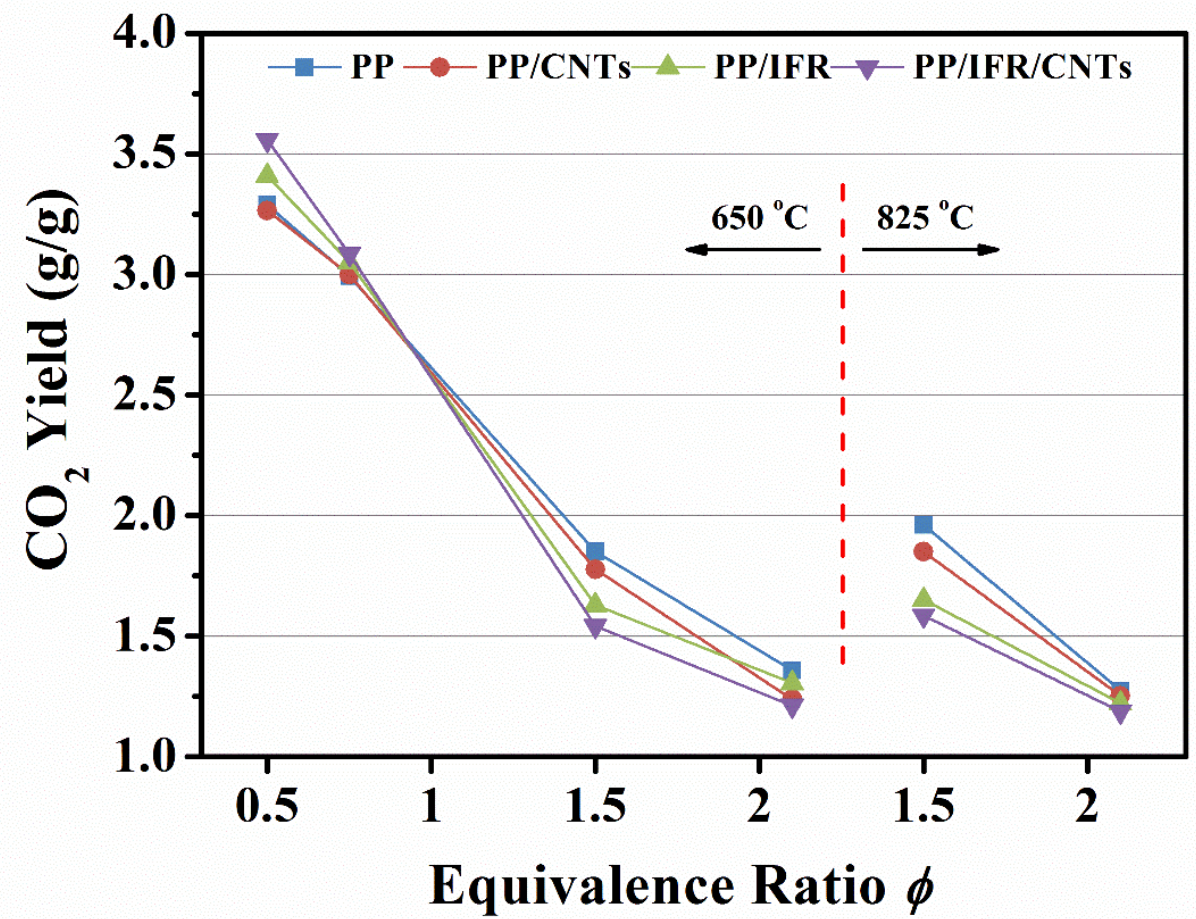

Figure $6 \mathrm{CO}_{2}$ yields of PP with IFR and CNTs additives 


\section{$\mathrm{CO}$ Yield and $\mathrm{CO}_{2} / \mathrm{CO}$ ratio}

Figure 7 shows the $\mathrm{CO}$ yield of various $\mathrm{PP}$ samples under the different fire conditions. As the equivalence ratio $\phi$ increase, the CO yield increase for all PP samples, and reach a maximum value at $\phi=1.5$. Similar results have been reported in low density polyethylene (LDPE) by Stec A.A. et al. [20]. It is apparent that the less oxygen supply leads to a lower combustion efficiency, and thus less $\mathrm{CO}$ is oxidized to $\mathrm{CO}_{2}$. The addition of IFR results in a higher $\mathrm{CO}$ yield compared to neat PP under each fire conditions, and the introduction of CNTs makes the growth larger. These results confirm the hinder effects of IFR and CNTs on the combustion of PP, which have been proved to benefit the thermal property and flame retardancy. It is quite clear from Figure 8 that the $\mathrm{CO}_{2} / \mathrm{CO}$ ratios of all samples under-ventilated conditions are all less than 10, which is much lower than that under well-ventilated conditions. Furthermore, both IFR and CNTs can decease the $\mathrm{CO}_{2} / \mathrm{CO}$ ratio, indicating much lower combustion efficiency and higher fire toxicity. The improvement in flame retardancy of PP composites with IFR and CNTs is based on higher fire toxicity according to the $\mathrm{CO}$ yield result and $\mathrm{CO}_{2} / \mathrm{CO}$ ratio.

The CO yield slightly increase at higher combustion temperature, especially for PP/IFR. At $825^{\circ} \mathrm{C}, \mathrm{PP} / \mathrm{IFR}$ and PP/IFR/CNTs have the lowest $\mathrm{CO}_{2} / \mathrm{CO}$ ratio (around 4 ) at $\phi=1.5$.

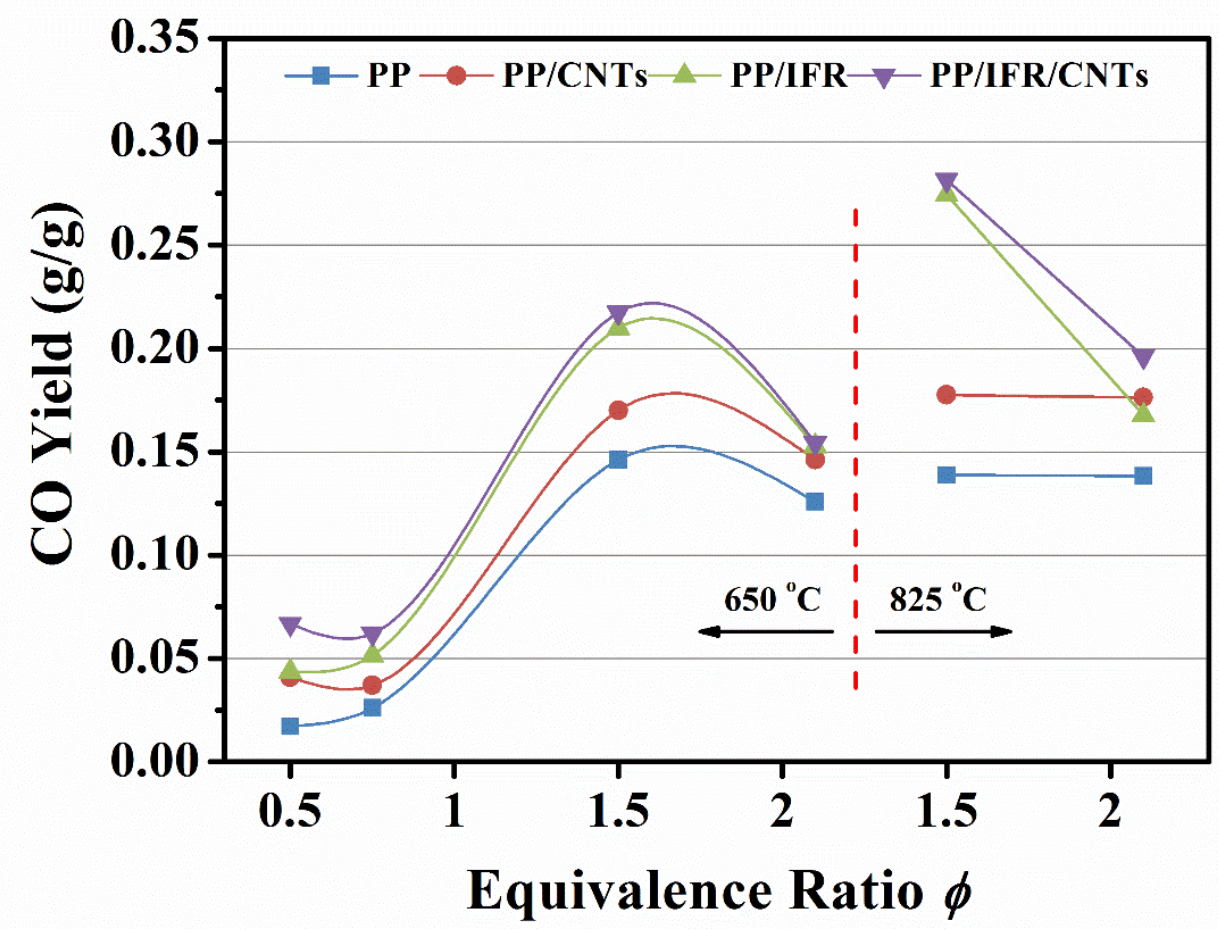

Figure 7 CO yields of PP with IFR and CNTs additives 


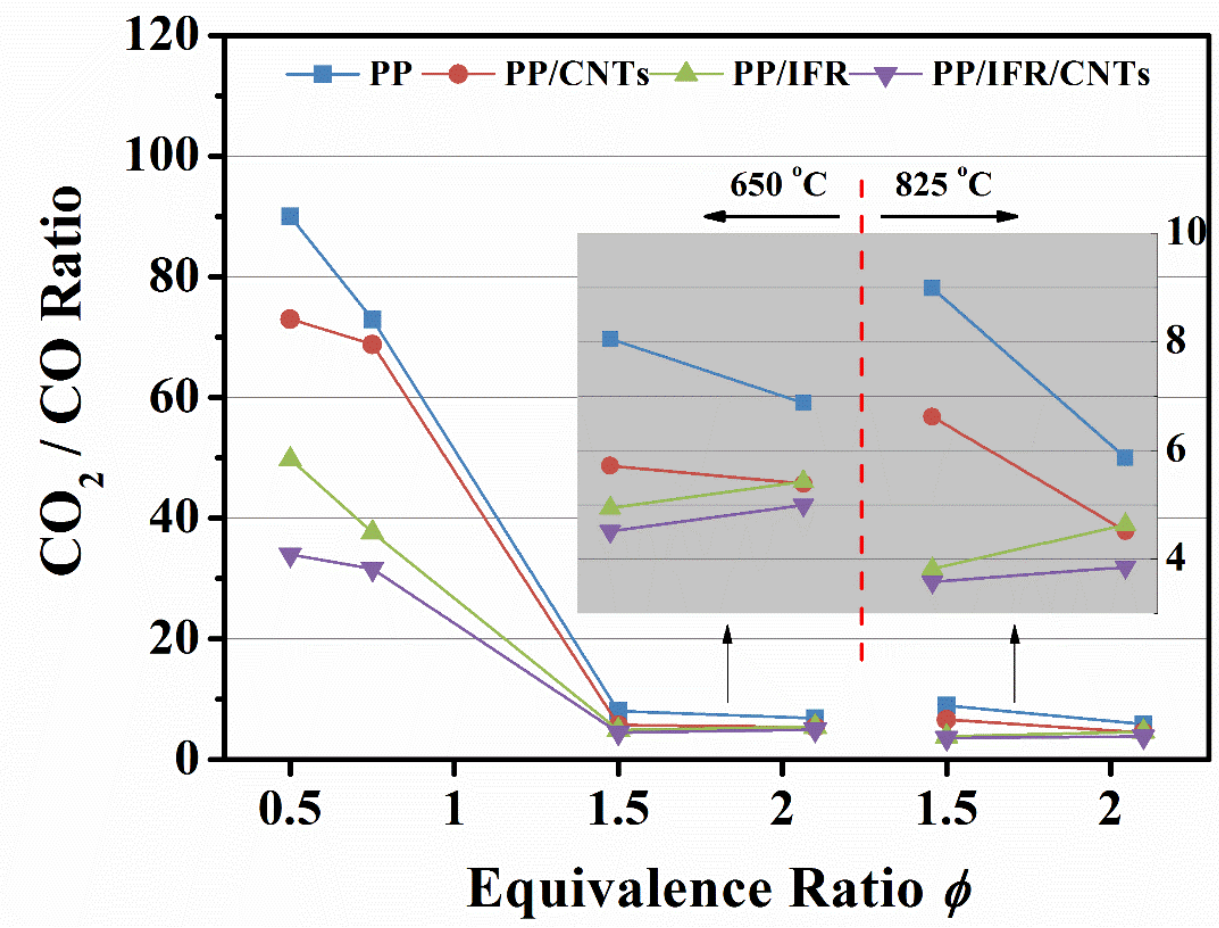

Figure $8 \mathrm{CO}_{2}$ and $\mathrm{CO}$ ratio of PP with IFR and CNTs additives

\section{Smoke Density}

The smoke density of the PP samples under different fire conditions is characterized by specific extinction area (SEA), as shown in Figure 9. The SEA of PP/IFR is almost twice the value of neat PP under each fire condition at $650^{\circ} \mathrm{C}$. The smoke density curves of PP and PP/IFR samples show very similar trend, and both of them reach the maximum smoke density at $\phi=1$. It is obvious that the addition of CNTs decrease the smoke density of both PP and PP/IFR samples under well-ventilated condition $(\phi<1)$. However, this beneficial effect becomes weaken continuously as the equivalence ratio increase, and finally turns to adverse effect. Furthermore, the combustion temperature also has a significant effect on the production of smoke, and at $825^{\circ} \mathrm{C}$, the smoke density of all the PP samples increases dramatically compared to these at $650^{\circ} \mathrm{C}$. 


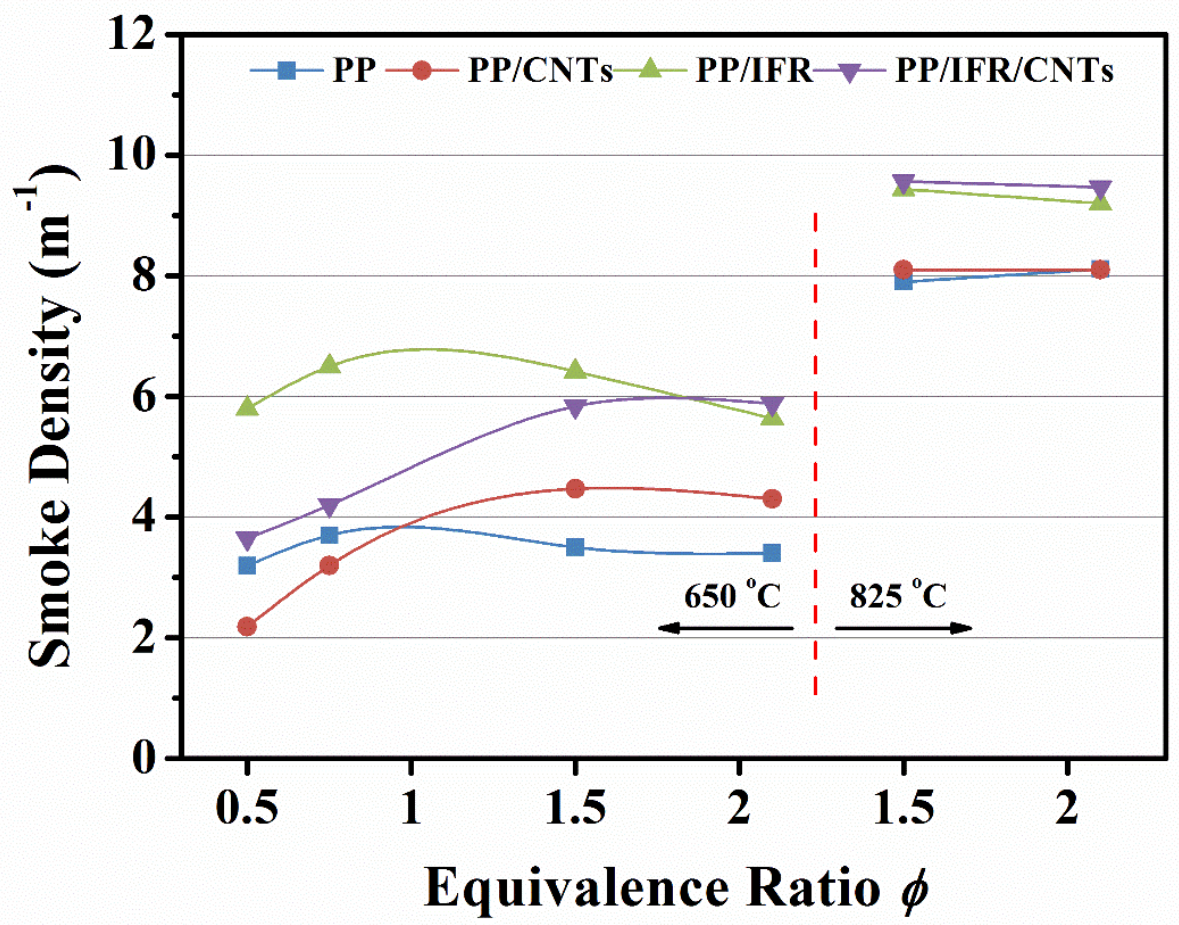

Figure 9 Smoke density of PP with IFR and CNTs additives

\section{$\mathrm{C}_{\mathrm{x}} \mathrm{H}_{\mathrm{y}}$ concentration}

Figure 10 presents the concentration of $\mathrm{C}_{\mathrm{x}} \mathrm{H}_{\mathrm{y}}$ released from the combustion of PP samples under different fire conditions. For well-ventilated conditions, a consistently low $\mathrm{C}_{x} \mathrm{H}_{y}$ concentration (less than $50 \mathrm{ppm}$ ) is observed for all PP samples. However, a much higher $\mathrm{C}_{\mathrm{x}} \mathrm{H}_{\mathrm{y}}$ concentration (over $800 \mathrm{ppm}$ ) for neat PP sample is obtained for under-ventilated conditions. The $\mathrm{C}_{\mathrm{x}} \mathrm{H}_{\mathrm{y}}$ concentration drops to $100-200 \mathrm{ppm}$ at $825^{\circ} \mathrm{C}$ with $\phi>1$. It can be supposed that more hydrocarbon was transformed to smoke particles or $\mathrm{CO}$ at higher temperature, which is in accordance with the smoke density results of PP samples. Furthermore, it is noticeable that the addition of CNTs decreases the $\mathrm{C}_{\mathrm{x}} \mathrm{H}_{\mathrm{y}}$ release, particularly for under-ventilated conditions, so it indicates that the presence of CNTs shows the similar effect on promoting the formation of smoke particulates from hydrocarbon, but this effect only exist when oxygen supply is not adequate. 


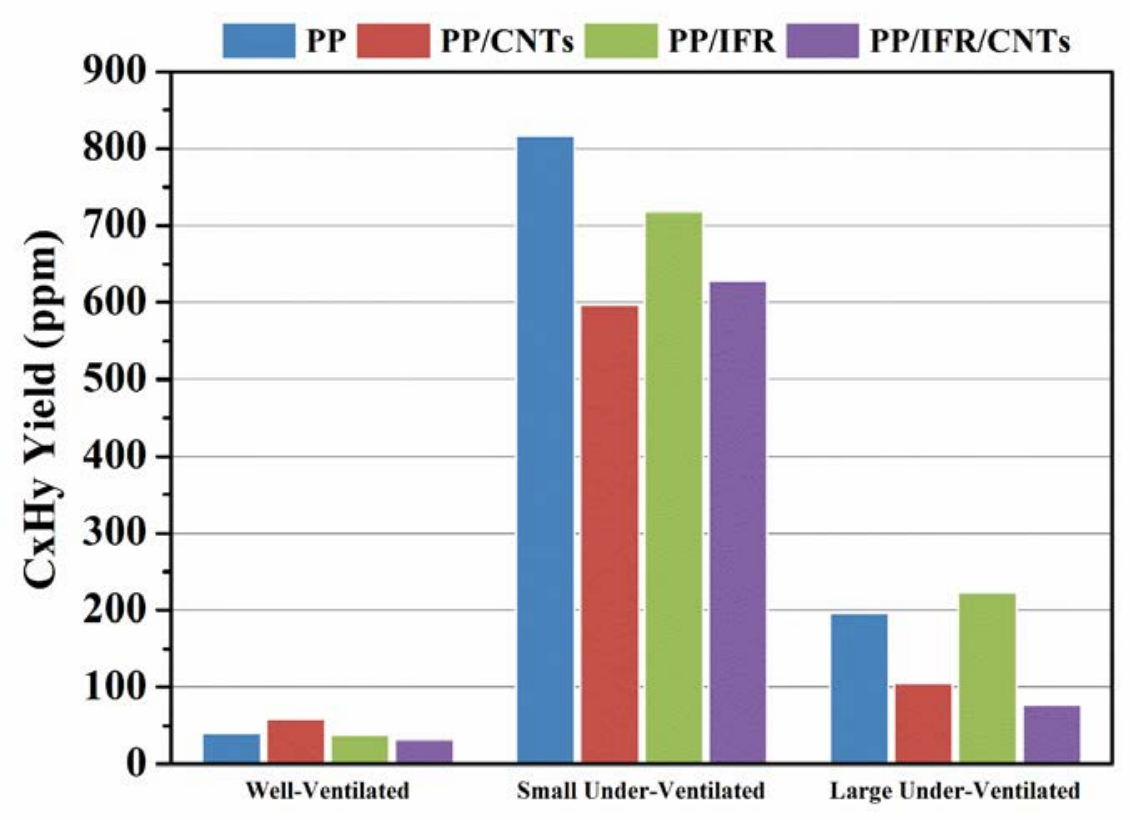

Figure 10 Hydrocarbon yield of PP with IFR and CNTs additives

\section{Smoke Particulates}

SEM was used to analyze the morphology and determine the extent of coagulation and agglomeration of the soot particulates collected from the PP samples under each fire condition.

As shown in Figure 11, the soot particles generated during the combustion of various PP samples under well-ventilated and under-ventilated conditions (both at $650{ }^{\circ} \mathrm{C}$ ) present similar morphology. However, the soot particles formed much larger sizes at higher temperature (825 ${ }^{\circ} \mathrm{C}$ ), especially for the PP/IFR and PP/IFR/CNTs samples. These results indicate that the agglomeration of soot particulates is most likely to occur under large under-ventilated condition. Furthermore, the presence of IFR have obvious promotion effect on the agglomeration degree of soot particulates under high temperature. 


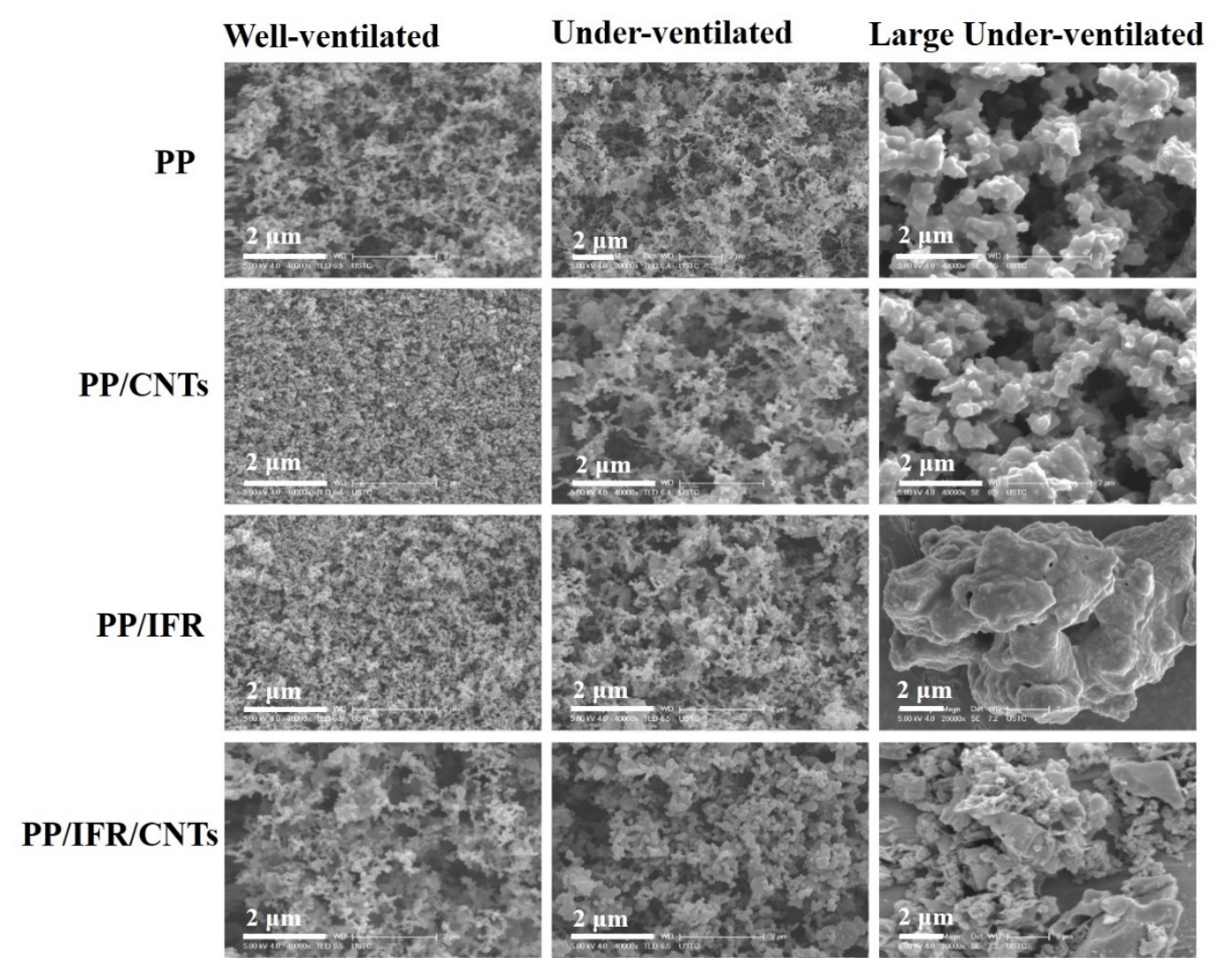

Figure 11

\section{Conclusions}

In this work, PP composites with CNTs and IFR were prepared, and thermal stability, flame retardant properties and combustion products of PP samples were studied. From the TGA data, the beneficial effect of IFR and CNTs on the thermal stability of PP samples is elucidated. The following SSTF tests revealed the toxic combustion effluent of PP composites with IFR and CNTs. For all combustion conditions, the addition of IFR and CNTs results in higher CO yield and much lower $\mathrm{CO}_{2} / \mathrm{CO}$ ratio, indicating the increase in toxicity of fire effluent. A reasonable explanation can be that, the influence of IFR, which forms a protective layer, seems to have a promotion effect on the yield of CO both under well-ventilated and under-ventilated condition. Likewise, the addition of CNTs, which forms a network in PP matrix, is supposed to strength the protective layer, and gives rise to the higher $\mathrm{CO}$ yield.

Due to the hinder effect of IFR on the combustion of PP samples, PP/IFR produces more smoke under all combustion condition compared to neat PP. However, the effect of CNTs on the smoke production changes from suppression to promotion as the equivalence ratio increases. The strong relationship between hydrocarbon and smoke production is revealed. Higher combustion temperature, as well as CNTs, suggests to accelerate the conversion of hydrocarbon to smoke particulates.

The soot particulates produced by the combustion of PP samples were collected and characterized by SEM. It is manifest that the agglomeration extent of particulates is dependent on the combustion temperature. Under higher temperature, a much more agglomerated 
morphology of soot particulates is observed. However, both IFR and CNTs show invisible influence on the morphology of the particulates.

It is also important to recognize that fire toxicity is mostly dependent on the combustion conditions. To make clear of the fire toxicity of materials under this particular combustion environment is necessary for fire engineers and material designers.

\section{Acknowledgements}

The work was financially supported by the National Natural Science Foundation of China (No. 51276054, 51303165, 21374111), and fundamental research funds for the central universities (WK2320000019).

\section{References}

[1] Lu, H.D. and C.A. Wilkie, Study on intumescent flame retarded polystyrene composites with improved flame retardancy. Polym Degrad Stab, 2010; 95(12): 2388-2395.

[2] McIntosh, D., V.N. Khabashesku, and E.V. Barrera, Nanocomposite fiber systems processed from fluorinated single-walled carbon nanotubes and a polypropylene matrix. Chem Mater, 2006; 18(19): 4561-4569.

[3] Antunes, M., M. Mudarra, and J.I. Velasco, Broad-band electrical conductivity of carbon nanofibre-reinforced polypropylene foams. Carbon, 2011; 49(2): 708-717.

[4] Kashiwagi, T., et al., Thermal and flammability properties of polypropylene/ carbon nanotube nanocomposites. Polymer, 2004; 45(12): 4227-4239.

[5] Huang, G.B., et al., Combination effect of carbon nanotubes with graphene on intumescent flame-retardant polypropylene nanocomposites. Compos Part a-Appl S, 2014; 59: 18-25.

[6] Du, B.X. and Z.P. Fang, Effects of carbon nanotubes on the thermal stability and flame retardancy of intumescent flame-retarded polypropylene. Polym Degrad Stab, 2011; 96(10): 1725-1731.

[7] Hull, T.R., et al., Factors affecting the combustion toxicity of polymeric materials. Polym Degrad Stab, 2007; 92(12): 2239-2246.

[8] Wichman, I.S., Material flammability, combustion, toxicity and fire hazard in transportation. Prog Energ Combust, 2003; 29(3): 247-299.

[9] Hull, T.R., J.M. Carman, and D.A. Purser, Prediction of CO evolution from small-scale polymer fires. Polym Int, 2000; 49(10): 1259-1265.

[10] Rhodes, J., C. Smith, and A.A. Stec, Characterisation of soot particulates from fire retarded and nanocomposite materials, and their toxicological impact. Polym Degrad Stab, 2011; 96(3): 277-284.

[11] Stec, A.A., T.R. Hull, and K. Lebek, Characterisation of the steady state tube furnace (ISO TS 19700) for fire toxicity assessment. Polym Degrad Stab, 2008; 93(11): 2058-2065.

[12] Purser, J.A., et al., Repeatability and reproducibility of the ISO/TS 19700 steady state tube furnace. Fire Safety J, 2013; 55: 22-34.

[13] Hull, T.R., A.A. Stec, and S. Nazare, Fire Retardant Effects of Polymer Nanocomposites. J Nanosci Nanotechno, 2009; 9(7): 4478-4486. 
[14] Hull, T.R., et al., An investigation into the decomposition and burning behaviour of Ethylene-vinyl acetate copolymer nanocomposite materials. Polym Degrad Stab, 2003; 82(2): 365-371.

[15] Hull, T.R., et al., Combustion toxicity of fire retarded EVA. Polym Degrad Stab, 2002; 77(2): 235-242.

[16] Stec, A.A. and J. Rhodes, Smoke and hydrocarbon yields from fire retarded polymer nanocomposites. Polym Degrad Stab, 2011; 96(3): 295-300.

[17] Wu, N. and R.J. Yang, Effects of metal oxides on intumescent flame-retardant polypropylene. Polym Advan Technol, 2011; 22(5): 495-501.

[18] Hapuarachchi, T.D., T. Peijs, and E. Bilotti, Thermal degradation and flammability behavior of polypropylene/clay/carbon nanotube composite systems. Polym Advan Technol, 2013; 24(3): 331-338.

[19] Patel, P., et al., Flammability properties of PEEK and carbon nanotube composites. Polym Degrad Stab, 2012; 97(12): 2492-2502.

[20] Stec, A.A., et al., The effect of temperature and ventilation condition on the toxic product yields from burning polymers. Fire Mater, 2008; 32(1): 49-60. 